\title{
Diabetes Mellitus, Obesity, and Risk of Pancreatic Ductal Adenocarcinoma: a Large Case-Control Study from Iran
}

\author{
Zahra Momayez Sanat ${ }^{1}$, Sahar Masoudi ${ }^{1}$, Masoumeh Mansouri ${ }^{1}$, Neda Ghamarzad Shishavan ${ }^{1}$, \\ Maryam Jameshorani ${ }^{2}$, Akram Pourshams 1,3,4,*
}

1. Liver and Pancreatobiliary Diseases Research Center, Digestive Diseases Research Institute, Tehran University of Medical Sciences, Tehran, Iran

2. Department of Internal Medicine, Zanjan University of Medical Sciences, Zanjan, Iran

3. Digestive Oncology Research Center, Digestive Diseases Research Institute, Tehran University of Medical Sciences, Tehran, Iran

4. Gastrointestinal and Liver Diseases Research Center, Guilan University of Medical Sciences, Rasht, Iran

* Corresponding Author:

Akram Pourshams, MD, MPH. Digestive Oncology Research Center, Liver, and Pancreatobiliary Diseases Research Center, Digestive Diseases Research Institute, Tehran University of Medical Sciences, Tehran, Iran Tel: + 982182415140

Fax: + 982182415500

Email: akrampourshams@gmail.com

Received: 07 Jul. 2020

Accepted: 11 Nov. 2020

\section{ABSTRACT}

\section{BACKGROUND}

Pancreatic cancer (PC) is a deadly, globally increasing cancer. The causes of PC are still insufficiently known, however smoking, diabetes mellitus (DM), and obesity have been identified as risk factors of PC, mostly in the developed countries. We evaluated these risk factors and their contribution to PC among an Iranian population.

\section{METHODS}

Cases and controls were selected from patients who were registered to a tertiary gastrointestinal diseases referral hospital in Tehran, Iran, from Jan 2012 to Jan 2018. Information on risk factors was collected by personal interview using a structured questionnaire. Logistic regression models were used to calculate adjusted odds ratios (AORs) and 95\% confidence intervals (CIs).

\section{RESULTS}

We recruited 470 new patients with histopathological PC diagnosis and 526 sex and age-matched controls. Cigarette-smoking [AOR: 1.65 (1.15-2.38)], opium use [AOR: $1.58(1.06-2.35)]$, DM [AOR: 1.99 (1.31-3.02)], and having a history of any cancer in a first-degree family member [AOR: $1.53(1.14-2.05)]$ were associated with an increased risk of PC. We did not find an association between obesity [AOR: $0.99(0.71-1.38)$ ] and PC. Approximately $4.6 \%, 5.9 \%, 8.2 \%$, and $10.9 \%$ risk of PC were related to cigarettesmoking, opium use, DM, and family history of any cancer, respectively.

\section{CONCLUSION}

This study supports that DM is associated with PC risk; however, similar to many studies in Asia, obesity is not associated with PC in Iranians. DM has the highest impact on PC development in Iranian women.

\section{KEYWORDS:}

Pancreas neoplasms, Obesity, Diabetes mellitus, Risk factor

Please cite this paper as:

Momayez Sanat Z, Masoudi S, Mansouri M, Ghamarzad Shishavan N, Jameshorani M, Pourshams A. Diabetes Mellitus, Obesity, and Risk of Pancreatic Ductal Adenocarcinoma: a Large Case-Control Study from Iran. Middle East J Dig Dis 2021;13:15-20. doi: 10.34172/ mejdd.2021.198.

\section{INTRODUCTION}

Pancreatic cancer (PC) was the seventh leading cause of cancer death in both 
men and women in 2018. ${ }^{1}$ PC remains one of the deadliest cancers globally, with almost as many deaths $(\mathrm{n}=432,000)$ as the incident cases $(\mathrm{n}=459,000)$ in 2018. ${ }^{1} \mathrm{PC}$ has an extremely poor prognosis and survival rate. The estimated 5 -year survival rate ranges between $2 \%$ and $9 \% .{ }^{2}$ The age-standardized incidence rates of $\mathrm{PC}$ range widely, the highest were found in men in Eastern Europe (9.9 per 100,000), and the lowest was reported in women in South-Central Asia (1 per 100,000). ${ }^{1}$ PC will surpass breast cancer to become the third leading cause of cancer deaths in the European Union ${ }^{3}$ as well as breast, prostate, and colorectal cancers to become the second cause of cancer-related death by 2030 in the United States. ${ }^{4}$ PC burden is expected to grow worldwide due to the growth and aging of the population, particularly in less developed countries where about $85 \%$ of the world's population reside. ${ }^{1,3-6}$ The differing PC burden between counties signifies that geographic diversity exists in the risk factors of PC. The causes of PC are still insufficiently known, although certain risk factors have been identified such as smoking, diabetes mellitus (DM), and obesity, mostly in high sociodemographic countries. ${ }^{2,6,7}$ The identification of risk factors for primary prevention is a major interest as a method to reduce burden of PC. To our knowledge this is the largest study in Middle East countries to evaluate independent risk factors as well as contribution of the risk factors in the PC development.

\section{MATERIALS AND METHODS}

This case-control study was approved by the Institutional Review Board of Digestive Disease Research Center, Tehran University of Medical Sciences (IRB number: IRB00001641, Federal wide Assurance number: FWA00015916). The methods of cases and controls recruitment as well as obtaining written informed consent from each participant were extensively explained elsewhere. ${ }^{8}$ Briefly, cases (those with pathology proved pancreatic adenocarcinoma) and controls (those with the normal pancreas and no other cancer) were selected from the patients who registered to the endoscopic ultrasonography of a university-affiliated hospital (Shariati Hospital) in Tehran, Iran, from Jan 2012 to Jan 2018. A structured, valid, and reliable questionnaire was used for data collection by a few trained interviewers. ${ }^{9}$ Weight and height were measured, and body mass index (BMI) was calculated using the weight before involuntary weight loss. BMI was categorized according to the WHO classification, and obesity was defined as BMI over $30 .{ }^{10}$ History of DM was considered positive if the study participant reported diagnosis by a physician. Considering DM is a risk for PC, and sometimes diabetes is an early sign of PC, we excluded from our analysis any diabetic patient who had DM two years prior to PC diagnosis. ${ }^{11}$ The date of cases being diagnosed with $\mathrm{PC}$ was defined as the index date. We have also investigated the association between current smoking, opium use, and family history of any kind of cancer in the first-degree relatives with the risk of PC in our study population to adjust our results. The main concern for the association of opium and case status is reverse causality, as patients may use opium to alleviate pain. To address reverse causality, we also excluded from analysis any opium use during 1 year prior to $\mathrm{PC}$ diagnosis. ${ }^{8}$

Participants' characteristics were examined for cases and controls, and sex by using $\mathrm{X}_{2}$ test for categorical variables and $t$ test for continuous variables.

We used unconditional logistic regression to calculate odds ratios $(\mathrm{OR})$ and $95 \%$ confidence intervals $(95 \% \mathrm{CI})$ for PC by the history of DM, adjusted for age, sex, smoking status, opium use, BMI, and family history of cancer in the first degree relatives. The population attributable risk percentage (PAR\%) for PC due to significant risk factors was calculated using the following equation:

$$
\mathrm{PAR} \%=\frac{\mathrm{P}_{\mathrm{e}}(\mathrm{OR}-1)}{\mathrm{P}_{\mathrm{e}}(\mathrm{OR}-1)+1}
$$

Where Pe is the prevalence of exposure among the control group and OR is the multivariable-adjusted OR calculated by logistic regression models. All statistical analyses were performed using Stata statistical software, version 11 (STATA Corp, College Station, TX), and $p<$ 0.05 was considered as statistically significant.

\section{RESULTS}

A total number of 470 patients whose pancreatic adenocarcinoma was diagnosed histopathologically (284 men, 60.4\%) and 526 (313 men, 59.5\%) hospital controls matched for sex and age were recruited to the study consecutively. Nearly $60 \%$ of the study participants in cases and control groups were male. The mean ages 
Table 1: Summaries of the prevalence of several risk factors in cases and controls

\begin{tabular}{|c|c|c|c|c|c|c|c|c|c|c|}
\hline \multirow[b]{2}{*}{ Variables } & & \multicolumn{4}{|c|}{ Case $(N=470)$} & \multicolumn{4}{|c|}{ Control $(\mathrm{N}=526)$} & \multirow[b]{2}{*}{$p$} \\
\hline & & Male(284) & $\begin{array}{c}\text { Female } \\
(186)\end{array}$ & $p$ & Total & Male(313) & $\begin{array}{l}\text { Female } \\
(213)\end{array}$ & $p$ & Total & \\
\hline \multirow{2}{*}{$\begin{array}{l}\text { Smoking N } \\
(\%)\end{array}$} & Current & $104(36.6)$ & $9(4.8)$ & \multirow{2}{*}{0.001} & $113(24.0)$ & $82(26.2)$ & $8(3.8)$ & \multirow{2}{*}{$<0.001$} & $90(17.1)$ & \multirow{2}{*}{0.00} \\
\hline & Never & $180(63.4)$ & $177(95.2)$ & & $357(76.0)$ & $231(73.8)$ & $205(96.2)$ & & $436(82.9)$ & \\
\hline \multirow{2}{*}{ Opium } & Ever & $72(25.4)$ & $3(1.6)$ & \multirow{2}{*}{$<0.001$} & $75(16.0)$ & $55(17.6)$ & $4(1.9)$ & \multirow{2}{*}{$<0.001$} & $59(11.2)$ & \multirow{2}{*}{0.02} \\
\hline & Never & $212(74.6)$ & $183(98.4)$ & & $395(84.0)$ & $258(82.4)$ & $209(98.1)$ & & $467(88.8)$ & \\
\hline \multirow{3}{*}{$\begin{array}{l}\text { Diabetes } \\
\text { mellitus } \\
\text { (>2 years) }\end{array}$} & Yes & 30 (10.6) & $40(21.5)$ & \multirow{3}{*}{0.001} & $70(14.9)$ & $19(6.1)$ & $28(13.1)$ & \multirow{3}{*}{0.005} & $47(8.9)$ & \multirow{3}{*}{0.00} \\
\hline & No & $254(89.4)$ & $146(78.5)$ & & $400(85.1)$ & 294 (93.9) & $185(86.9)$ & & $479(91.1)$ & \\
\hline & No & $262(92.3)$ & 161 (86.6) & & $423(90.0)$ & $300(95.8)$ & $195(91.5)$ & & $495(94.1)$ & \\
\hline \multirow{2}{*}{$\operatorname{BMI}\left(\mathrm{Kg} / \mathrm{m}^{2}\right)^{*}$} & $<30$ & $235(86.2)$ & $136(73.9)$ & \multirow{2}{*}{$<0.001$} & 374 (81.3) & $268(87.9)$ & 151 (71.6) & \multirow{2}{*}{0.001} & $419(81.2)$ & \multirow{2}{*}{0.967} \\
\hline & $\geq 30$ & $38(13.8)$ & $48(26.1)$ & & $86(18.7)$ & $37(12.1)$ & $60(28.4)$ & & $97(18.8)$ & \\
\hline \multirow{2}{*}{$\begin{array}{l}\text { Family history } \\
\text { of any cancer } \\
\text { (first degree) }\end{array}$} & Yes & $84(29.6)$ & $54(29.0)$ & \multirow{2}{*}{0.942} & $138(29.4)$ & $68(21.7)$ & $45(21.1)$ & \multirow{2}{*}{0.870} & $113(21.5)$ & \multirow{2}{*}{0.00} \\
\hline & No & $200(70.4)$ & $132(71.0)$ & & $332(70.6)$ & $245(78.3)$ & $168(78.9)$ & & $413(78.5)$ & \\
\hline \multirow{8}{*}{$\begin{array}{l}\text { Cancer sites } \\
\text { in family } \\
\text { members }\end{array}$} & Gastric & & & & $9(6.52)$ & & & & $7(6.2)$ & \\
\hline & $\begin{array}{l}\text { Esopha- } \\
\text { geal }\end{array}$ & & & & $6(4.35)$ & & & & $5(4.4)$ & \\
\hline & Colon & & & & $14(10.14)$ & & & & $9(8.0)$ & \\
\hline & Breast & & & & $10(7.25)$ & & & & $4(3.5)$ & \\
\hline & Prostate & & & & $10(7.25)$ & & & & $3(2.7)$ & \\
\hline & Pancreas & & & & $8(5.80)$ & & & & $2(1.7)$ & \\
\hline & Lung & & & & $11(7.97)$ & & & & $10(8.8)$ & \\
\hline & Other & & & & $70(50.72)$ & & & & $73(64.6)$ & \\
\hline
\end{tabular}

*Body Mass Index

were $64.1 \pm 11.6$ years in cases and $62.7 \pm 13.2$ years in the controls, with no statistically significant difference $(\mathrm{t}$ test; $p=0.074) .51$ patients $(10.8 \%)$ developed PC before the age of 50 , and 241 patients (51.3\%) were older than 65 years.

Details of risk factors among cases and controls are listed in Table 1.

After adjustment for potential confounders, cigarette smoking [OR; 1.65 (1.15-2.38)], opium use [OR; 1.58 (1.06 -2.35)], DM [OR 1.99 (1.31-3.02)], and having a family history of any kind of cancer in a first-degree relative [OR; 1.53 (1.14-2.05)] were associated with an increased risk of $\mathrm{PC}$. We did not find an association between obesity [OR; $0.99(0.71-1.38)$ ] and PC (table 2). Approximately $4.6 \%, 5.9 \%, 8.2 \%$, and $10.9 \%$ of PC cases in this study were related to cigarette smoking, opium use, DM, and family history of any cancer, respectively.

The population attributable risk percent for $\mathrm{PC}$ among Iranian are shown in table 3.

\section{DISCUSSION}

This is the first large prospective study of the association between cigarette smoking, opium use, DM, obesity, and family history of cancer with the risk of PC in a Middle Eastern country. We observed significantly increased risks of PC in those who reported tobacco smoking and opium use, as well as those who have diabetes for the long term or have a first-degree relative with any kind of cancer. Cigarette smoking and DM are two risk factors that have been consistently associated with PC. ${ }^{12-14}$ In multiple comprehensive meta-analyses and pooled analysis, summary risk estimates of smoking for PC were between 1.6 and 2.2 for current smokers and between 1.1 and 1.2 for former smokers. ${ }^{15-19}$ Smoking is associated with a two-fold increased risk of PC, and that the risk increases with the number of cigarettes smoked and duration of smoking. ${ }^{19}$ The evidence is consistent and strong, and justified by the numerous reports showing a positive association between smoking and risk of PC in different countries and regions. ${ }^{16-19}$ Estimated population-attributable fractions 
Table 2: Effect of potential risk factors on PC in logistic regression analysis

\begin{tabular}{|c|c|c|c|c|c|c|c|}
\hline \multirow{2}{*}{ Variables } & & \multicolumn{3}{|c|}{ Crude OR (95\% CI) } & \multicolumn{3}{|c|}{ Full adjusted $^{* *}$ OR $(95 \%$ CI $)$} \\
\hline & & Male & Female & Total & Male & Female & Total \\
\hline Smoking & $\begin{array}{l}\text { Current/ } \\
\text { Never }\end{array}$ & $1.62(1.14-2.31)$ & $1.30(0.49-3.44)$ & $1.53(1.12-2.09)$ & $1.73(1.16-2.57)$ & $1.47(0.53-4.05)$ & $1.65(1.15-2.38)$ \\
\hline Opium & $\begin{array}{l}\text { Ever/ } \\
\text { Never }\end{array}$ & $1.59(1.07-2.36)$ & $0.85(0.18-3.87)$ & $1.50(1.04-2.17)$ & $1.70(1.13-2.57)$ & $0.80(0.17-3.80)$ & $1.58(1.06-2.35)$ \\
\hline $\begin{array}{l}\text { Diabetes Mel- } \\
\text { litus (>2 years) }\end{array}$ & Yes/No & $1.82(1.01-3.32)$ & $1.81(1.06-3.07)$ & $1.78(1.20-2.64)$ & $1.99(1.05-3.75)$ & $1.98(1.13-3.47)$ & $1.99(1.31-3.02)$ \\
\hline BMI* & $\geq 30 /<30$ & $1.15(0.71-1.87)$ & $0.88(0.56-1.38)$ & $0.99(0.72-1.37)$ & $1.15(0.70-1.89)$ & $0.88(0.56-1.41)$ & $0.99(0.71-1.38)$ \\
\hline $\begin{array}{l}\text { Family History } \\
\text { of Cancer }\end{array}$ & Yes/No & $1.51(1.04-2.19)$ & $1.52(0.96-2.41)$ & $1.51(1.14-2.02)$ & $1.58(1.08-2.31)$ & $1.53(0.96-2.43)$ & $1.53(1.14-2.05)$ \\
\hline
\end{tabular}

**Included sex, age, BMI, history of diabetes mellitus, smoking, family history of cancer, opium *Body Mass Index

Table 3: Population attributable risk percentage (PAR\%)

\begin{tabular}{lccc}
\hline Risk factors & Total & Male & Female \\
\hline Smoking & $4.6 \%$ & $16 \%$ & $2 \%$ \\
\hline Opium use & $5.9 \%$ & $11 \%$ & - \\
\hline Diabetes mellitus & $8.2 \%$ & $6 \%$ & $12 \%$ \\
\hline Family history of any cancer & $10.9 \%$ & $11 \%$ & $10 \%$ \\
\hline
\end{tabular}

of tobacco smoking with PC is $11-32 \% .^{7}$ Our results support the existing evidence about the association between tobacco smoking and PC. The contribution of smoking in PC development in our men (16\%) is eight times higher than our women, which represents much more smoking among Iranian men than Iranian women. While cigarette smoking has the highest attributable fraction for PC in our men, it has the lowest attributable fraction in our women (table 3$)$. A total of 70 (14.9\%) cases and 47 (8.9 $\%$ ) controls reported a diagnosis of DM, more than 2 years before PC diagnosis (or interview, for controls), corresponding to an OR of 1.99 (95\% CI, 1.31-3.02). Our results, in concordance with all worldwide reports, show long-term diabetes is associated with an increased risk of PC. ${ }^{7,12,13}$ Global age-standardised diabetes prevalence increased from $4.3 \%(95 \% \mathrm{CI} ; 2.4-7.0)$ in 1980 to $9.0 \%$ (95\% CI;7.2-11.1) in 2014 in men, and from 5.0\% (95\% CI; 2.9-7.9) to 7.9\% (95\% CI;6.4-9.7) in women. ${ }^{20}$ DM prevalence in Iran has been high $(11.4 \%$ of the adult population in 2011), and is constantly increasing. ${ }^{21,22}$ The high prevalence of DM makes it an important contributor to the burden of PC in Iran as well as worldwide. It is estimated that $1 \%$ to $16 \%$ of all PC might be attributable to DM. ${ }^{7} \mathrm{DM}$ is associated with a 2.6 fold increased risk of PC. ${ }^{23}$ Overlay $8.2 \%$ of all Iranian PCs is attributable to DM, the highest risk fraction among women (table 3).

For the first time, our group detected an association between opium consumption and PC risk in two studies (a case-control and a large-scale prospective cohort). ${ }^{8,24} \mathrm{We}$ reported a statistically significant excess risk of PC in opium users; OR $=1.91$ (95\% CI 1.06-3.43) in the casecontrol study and $\mathrm{HR}=2.75(95 \% \mathrm{CI}, 1.14-6.64)$ in the cohort study. ${ }^{8,24}$ Opium is considered as a genotoxic substance, ${ }^{25}$ and opioid receptors are present in the human pancreas, ${ }^{26}$ therefore, it is conceivable that activation of the pancreas opioid receptor could induce tumor genesis. Opium consumption could be responsible for $11 \%$ of PC in Iranian men but has no attribution in the PC development among Iranian women (table 3).

Results of the studies on the association between obesity and $\mathrm{PC}$ risk have been inconsistent. Multiple studies, mostly from western countries, reported a positive association between obesity and $\mathrm{PC}$ risk. ${ }^{27-31}$ However, no association was found in other studies. ${ }^{32,33}$ Most prospective cohort studies and pooled analyses in East-Asia did not find a positive association between obesity and risk of PC. ${ }^{34}$ In a population-based cohort study in Japan (224 cases), a statistically significant excess risk of PC was associated with current smoking $(\mathrm{HR}=1.8, \mathrm{CI} 1.1-3.0)$ and a history of diabetes $(\mathrm{HR}=2.1, \mathrm{CI} 1.3-3.5)$ among men; however, BMI was inversely associated with the risk of PC among men, especially among current smokers or patients with diabetes and there was no association between obesity and PC among women. ${ }^{35}$ Meanwhile, obesity is common in Iran, ${ }^{36,37}$ but the same as in most Asian countries, obesity is not associated with PC risk . ${ }^{34,35}$

We observed a significantly increased risk of PC among subjects (both men and women) who reported 
a first-degree relative with any cancer (table 2). The positive effect of a family history of any cancer among first-degree relatives and risk of PC has been reported already. ${ }^{23,38,39}$ Individuals with a family history of PC have nearly a two-fold increased risk for developing PC compared with those without such a history. ${ }^{40}$ Several genetic factors have been identified for PC. ${ }^{41,42}$ Mutations in genes responsible for hereditary cancer syndromes such as BRCA1/2 may partly explain these associations. ${ }^{42}$ We estimated $10.9 \%$ of all our PCs are attributable to a hereditary risk factor (table 3 ).

\section{CONCLUSION}

This study supports DM is associated with PC risk; however, similar to many other studies from Asian countries, obesity is not associated with PC in our population. DM has the highest impact on PC development in Iranian women.

\section{ETHICAL APPROVAL}

There is nothing to be declared.

\section{CONFLICT OF INTEREST}

The authors declare no conflict of interest related to this work.

\section{REFERENCES}

1. Bray F, Ferlay J, Soerjomataram I, Siegel RL, Torre LA, Jemal A. Global cancer statistics 2018: GLOBOCAN estimates of incidence and mortality worldwide for 36 cancers in 185 countries. CA Cancer J Clin 2018;68:394-424. doi: 10.3322/ caac. 21492.

2. Ilic M, Ilic I. Epidemiology of pancreatic cancer. World J Gastroenterol 2016;22:9694-705. doi: 10.3748/wjg.v22.i44.9694.

3. Ferlay J, Partensky C, Bray F. More deaths from pancreatic cancer than breast cancer in the EU by 2017. Acta Oncol 2016;55:1158-60. doi: 10.1080/0284186X.2016.1197419.

4. Rahib L, Smith BD, Aizenberg R, Rosenzweig AB, Fleshman JM, Matrisian LM. Projecting cancer incidence and deaths to 2030: the unexpected burden of thyroid, liver, and pancreas cancers in the United States. Cancer Res 2014;74:2913-21. doi: 10.1158/0008-5472.CAN-14-0155.

5. Saad AM, Turk T, Al-Husseini MJ, Abdel-Rahman O. Trends in pancreatic adenocarcinoma incidence and mortality in the United States in the last four decades; a SEER-based study. BMC Cancer 2018;18:688. doi: 10.1186/s12885-018-4610-4.

6. Wong MCS, Jiang JY, Liang M, Fang Y, Yeung MS, Sung JJY. Global temporal patterns of pancreatic cancer and association with socioeconomic development. Sci Rep 2017;7:3165. doi: 10.1038/s41598-017-02997-2.
7. Maisonneuve P, Lowenfels AB. Risk factors for pancreatic cancer: a summary review of meta-analytical studies. Int J Epidemiol 2015;44:186-98. doi: 10.1093/ije/dyu240.

8. Shakeri R, Kamangar F, Mohamadnejad M, Tabrizi R, Zamani F, Mohamadkhani A, et al. Opium use, cigarette smoking, and alcohol consumption in relation to pancreatic cancer. Medicine (Baltimore) 2016;95:e3922. doi: 10.1097/MD.0000000000003922.

9. Farrokhzad S, Nedjat S, Kamangar F, Kamali M, Malekzadeh $\mathrm{R}$, Pourshams A. Validity and reliability of a questionnaire designed to assess risk factors of pancreatic cancer in Iran. Arch Iran Med 2014;17:102-5.

10. WHO.int. BMI classification. Geneva: World health organization. 2006. [Updated 01/12/2012].

11. Risch HA. Diabetes and Pancreatic Cancer: Both Cause and Effect. J Natl Cancer Inst 2019;111:1-2. doi: 10.1093/jnci/djy093.

12. Bosetti C, Rosato V, Li D, Silverman D, Petersen GM, Bracci PM, et al. Diabetes, antidiabetic medications, and pancreatic cancer risk: an analysis from the International Pancreatic Cancer Case-Control Consortium. Ann Oncol 2014;25:2065-72. doi: 10.1093/annonc/mdu276.

13. Li D, Tang H, Hassan MM, Holly EA, Bracci PM, Silverman DT. Diabetes and risk of pancreatic cancer: a pooled analysis of three large case-control studies. Cancer Causes Control 2011;22:189-97. doi: 10.1007/s10552-010-9686-3.

14. Korc M, Jeon CY, Edderkaoui M, Pandol SJ, Petrov MS, Consortium for the Study of Chronic Pancreatitis D, et al. Tobacco and alcohol as risk factors for pancreatic cancer. Best Pract Res Clin Gastroenterol 2017;31:52936. doi: 10.1016/j.bpg.2017.09.001.

15. Iodice $\mathrm{S}$, Gandini $\mathrm{S}$, Maisonneuve $\mathrm{P}$, Lowenfels AB. Tobacco and the risk of pancreatic cancer: a review and metaanalysis. Langenbecks Arch Surg 2008;393:535-45. doi: 10.1007/s00423-007-0266-2.

16. Ansary-Moghaddam A, Huxley R, Barzi F, Lawes C, Ohkubo T, Fang X, et al. The effect of modifiable risk factors on pancreatic cancer mortality in populations of the Asia-Pacific region. Cancer Epidemiol Biomarkers Prev 2006;15:2435-40. doi: 10.1158/1055-9965.EPI-06-0368.

17. Katanoda K, Marugame T, Saika K, Satoh H, Tajima K, Suzuki T, et al. Population attributable fraction of mortality associated with tobacco smoking in Japan: a pooled analysis of three large-scale cohort studies. J Epidemiol 2008;18:251-64. doi: 10.2188/jea.je2007429.

18. Lynch SM, Vrieling A, Lubin JH, Kraft P, Mendelsohn JB, Hartge P, et al. Cigarette smoking and pancreatic cancer: a pooled analysis from the pancreatic cancer cohort consortium. Am J Epidemiol 2009;170:403-13. doi: 10.1093/aje/kwp134.

19. Bosetti C, Lucenteforte E, Silverman DT, Petersen G, Bracci PM, Ji BT, et al. Cigarette smoking and pancreatic cancer: an analysis from the International Pancreatic Cancer Case-Control Consortium (Panc4). Ann Oncol 2012;23:1880-8. doi: 10.1093/annonc/mdr541.

20. Worldwide trends in diabetes since 1980: a pooled 
analysis of 751 population-based studies with 4.4 million participants. Lancet 2016;387:1513-30. doi: 10.1016/S0140-6736(16)00618-8.

21. Noshad S, Afarideh M, Heidari B, Mechanick JI, Esteghamati A. Diabetes Care in Iran: Where We Stand and Where We Are Headed. Ann Glob Health 2015;81:839-50. doi: 10.1016/j.aogh.2015.10.003.

22. Rashedi V, Asadi-Lari M, Delbari A, Fadayevatan R, Borhaninejad V, Foroughan M. Prevalence of diabetes type 2 in older adults: Findings from a large population-based survey in Tehran, Iran (Urban HEART-2). Diabetes Metab Syndr 2017;11:S347-s50. doi: 10.1016/j.dsx.2017.03.014.

23. Hassan MM, Bondy ML, Wolff RA, Abbruzzese JL, Vauthey JN, Pisters PW, et al. Risk factors for pancreatic cancer: case-control study. Am J Gastroenterol 2007;102:2696707. doi: 10.1111/j.1572-0241.2007.01510.x.

24. Moossavi S, Mohamadnejad M, Pourshams A, Poustchi H, Islami F, Sharafkhah M, et al. Opium Use and Risk of Pancreatic Cancer: A Prospective Cohort Study. Cancer Epidemiol Biomarkers Prev 2018;27:268-73. doi: 10.1158/1055-9965.EPI-17-0592.

25. Li JH, Lin LF. Genetic toxicology of abused drugs: a brief review. Mutagenesis 1998;13:557-65. doi: 10.1093/mutage/13.6.557.

26. Peng J, Sarkar S, Chang SL. Opioid receptor expression in human brain and peripheral tissues using absolute quantitative real-time RT-PCR. Drug Alcohol Depend 2012;124:223-8. doi: 10.1016/j.drugalcdep.2012.01.013.

27. Carreras-Torres R, Johansson M, Gaborieau V, Haycock PC, Wade KH, Relton CL, et al. The Role of Obesity, Type 2 Diabetes, and Metabolic Factors in Pancreatic Cancer: A Mendelian Randomization Study. J Natl Cancer Inst 2017;109: djx012. doi: 10.1093/jnci/djx012.

28. Calle EE, Rodriguez C, Walker-Thurmond K, Thun MJ. Overweight, obesity, and mortality from cancer in a prospectively studied cohort of US adults. New Engl J Med 2003;348:1625-38. doi: 10.1056/NEJMoa021423.

29. Michaud DS, Giovannucci E, Willett WC, Colditz GA, Stampfer MJ, Fuchs CS. Physical activity, obesity, height, and the risk of pancreatic cancer. JAMA 2001;286:921-9. doi: 10.1001/jama.286.8.921.

30. Pan SY, Johnson KC, Ugnat AM, Wen SW, Mao Y. Association of obesity and cancer risk in Canada. Am J Epidemiol 2004;159:259-68. doi: 10.1093/aje/kwh041.

31. Pourshams A, Sepanlou SG, Ikuta KS, Bisignano C, Safiri S, Roshandel G, et al. The global, regional, and national burden of pancreatic cancer and its attributable risk factors in 195 countries and territories, 1990-2017: a systematic analysis for the Global Burden of Disease Study 2017. Lancet Gastroenterol Hepatol 2019;4:93447. doi: 10.1016/S2468-1253(19)30347-4.

32. Nilsen TIL, Vatten LJ. A prospective study of lifestyle factors and the risk of pancreatic cancer in Nord-Trøndelag, Norway. Cancer Causes Control 2000;11:64552. doi: 10.1023/a:1008916123357.
33. Sinner PJ, Schmitz KH, Anderson KE, Folsom AR. Lack of association of physical activity and obesity with incident pancreatic cancer in elderly women. Cancer Epidemiol Biomarkers Prev 2005;14:1571-3. doi: 10.1158/10559965.EPI-05-0036.

34. Lee I, Sesso H, Oguma Y, Paffenbarger Jr R. Physical activity, body weight, and pancreatic cancer mortality. Br J Cancer 2003;88:679-83. doi: 10.1038/ sj.bjc. 6600782 .

35. Luo J, Iwasaki M, Inoue M, Sasazuki S, Otani T, Ye W, et al. Body mass index, physical activity and the risk of pancreatic cancer in relation to smoking status and history of diabetes: a large-scale population-based cohort study in Japan--the JPHC study. Cancer Causes Control 2007;18:603-12. doi: 10.1007/s10552-007-9002-z.

36. Bahrami H, Sadatsafavi M, Pourshams A, Kamangar F, Nouraei M, Semnani S, et al. Obesity and hypertension in an Iranian cohort study; Iranian women experience higher rates of obesity and hypertension than American women. BMC public health 2006;6:158. doi: 10.1186/14712458-6-158.

37. Bakhshi E, Koohpayehzadeh J, Seifi B, Rafei A, Biglarian A, Asgari F, et al. Obesity and Related Factors in Iran: The STEPS Survey, 2011. Iran Red Crescent Med J 2015;17:e22479. doi: 10.5812/ircmj.17(6)2015.22479.

38. Hiripi E, Lorenzo Bermejo J, Li X, Sundquist J, Hemminki $\mathrm{K}$. Familial association of pancreatic cancer with other malignancies in Swedish families. Br J Cancer 2009;101:17927. doi: 10.1038/sj.bjc. 6605363 .

39. Jacobs EJ, Chanock SJ, Fuchs CS, Lacroix A, McWilliams RR, Steplowski E, et al. Family history of cancer and risk of pancreatic cancer: a pooled analysis from the Pancreatic Cancer Cohort Consortium (PanScan). Int $J$ Cancer 2010;127:1421-8. doi: 10.1002/ijc.25148.

40. Permuth-Wey J, Egan KM. Family history is a significant risk factor for pancreatic cancer: results from a systematic review and meta-analysis. Fam Cancer 2009;8:109-17. doi: 10.1007/s10689-008-9214-8.

41. Alimirzaie S, Mohamadkhani A, Masoudi S, Sellars E, Boffetta P, Malekzadeh R, et al. Mutations in Known and Novel cancer Susceptibility Genes in Young Patients with Pancreatic Cancer. Arch Iran Med 2018;21:228-33.

42. Lal G, Liu G, Schmocker B, Kaurah P, Ozcelik H, Narod SA, et al. Inherited predisposition to pancreatic adenocarcinoma: role of family history and germ-line p16, BRCA1, and BRCA2 mutations. Cancer Res 2000;60:409-16. 